Agrotrópica 32(2): 119 - 126. 2020.

Centro de Pesquisas do Cacau, Ilhéus, Bahia, Brasil

\title{
TRATAMENTO SANITÁRIO E QUALIDADE FISIOLÓGICA DE SEMENTES DE PALMA-DE-ÓLEO RECÉM-COLHIDAS E ARMAZENADAS SUBMETIDAS A DIFERENTES FUNGICIDAS
}

\author{
Alex Queiroz Cysne ${ }^{1}$, Ricardo Lopes ${ }^{2}$, Raimundo Nonato Vieira da Cunha ${ }^{2}$ \\ ${ }^{1}$ Embrapa Agroindústria Tropical, Sara Mesquita, 2.270, Bairro Planalto do Pici, 60511-110, Fortaleza, Ceará, Brasil. \\ alex.cysne@embrapa.br. ${ }^{2}$ Embrapa Amazônia Ocidental, Rod. AM 010, km 29, Zona Rural, 69010-970, Manaus, AM, \\ Brasil.ricardo.lopes@embrapa.br; raimundo.vieira@embrapa.br.
}

\begin{abstract}
A qualidade sanitária e a qualidade fisiológica de sementes de Palma-de-Óleo é essencial para o estabelecimento de áreas de plantio. Assim, objetivou-se testar diferentes fungicidas quanto ao seu efeito sobre a população de fungos presente em sementes de Palma-de-Óleo, recém colhidas e armazenadas por seis meses. A análise sanitária das sementes foi realizada pelo método de incubação em papel filtro (Blotter Test). Os princípios ativos testados foram Carboxina + Tiram, Carbendazim, Cloridrato de Cartape, Clorotalonil + Tiofanato-metílico, Pencicurom e Tebuconazol + Trifloxistrobina, acrescido de uma testemunha (sem aplicação). O delineamento utilizado foi o inteiramente casualizado em esquema fatorial 7 (tratamentos) x 2 (tempos), com dez repetições. O produto a base de Clorotalonil+Tiofanato-metílico reduziu significativamente a incidência de fungos em sementes de Palma-de-Óleo nas duas épocas avaliadas. O princípio ativo Tebuconazol+Trifloxistrobina obteve resultados satisfatórios ao reduzir a população de fungos em sementes de Palma-de-Óleo analisadas imediatamente após colheita.
\end{abstract}

Palavras-chave: Dendezeiro, Elaeis guineensis, fungos, manejo, princípios ativos.

\section{Health treatment and physiological quality of Oil palm seeds newly harvested} and stored submitted to different fungicides. The sanitary quality and the physiological quality of oil palm seeds are essential for the establishment of planting areas. Thus, the objective was to test different fungicides for their effect on the population of fungi present in oil palm seeds, freshly harvested and stored for six months. The seed health analysis was conducted by the method of incubation on paper filter (Blotter test). The active principles tested were Carboxine + Tiram, Carbendazim, Cartape Hydrochloride, Chlorothalonil + Thiophanatemethyl, Pencicurom and Tebuconazole + Trifloxystrobin, plus a control (no application). The design was completely randomized in factorial 7 (treatments) $\times 2$ (times), with ten replications. The product based on Chlorothalonil + Thiophanate-methyl reduced significantly the incidence of fungi in oil palm seeds in the two evaluated periods. The active principle Tebuconazol + Trifloxystrobin obtained satisfactory results when reducing the fungus population in oil palm seeds analyzed immediately after harvest.

Key words: Active principles, Elaeis guineensis, fungi, management, oil palm. 


\section{Introdução}

A Palma-de-Óleo (Elaeis guineensis Jacq.) é responsável pela maior parte $(38,9 \%$ do total) da produção mundial de óleo vegetal, com 78,8 milhões de toneladas (70,46 de óleo de palma e 8,32 de óleo de palmiste) produzidas na safra 2017/18 (USDA, 2019). Esta cultura destaca-se entre as espécies oleaginosas por sua alta capacidade de produção de óleo por unidade de área (Rios et al., 2012) e por ser a de menor custo de produção (Zimmer, 2009).

As áreas de cultivo comercial da Palma-de-Óleo são estabelecidas, predominantemente, com mudas de cultivares híbridas intraespecíficas do tipo Tenera. $\mathrm{Na}$ produção dessas mudas são utilizadas sementes obtidas com condições controladas, desde o isolamento das inflorescências no campo de genitores até a germinação em laboratório, dessa forma, garantindo a qualidade genética, fisiológica e sanitária das mesmas.

Especificamente, quanto à qualidade sanitária, para evitar a deterioração de sementes, anormalidades e lesões em plântulas, deve-se realizar o adequado manejo fitossanitário dos principais fungos com potencial patogênico durante o armazenamento e a germinação das sementes. Estes microrganismos representam um considerável grupo que respondem por diversas enfermidades e danos que afetam as sementes (Galli, Panizi e Vieira 2007).

O tratamento químico de sementes possibilita proteger contra a ação de patógenos a ela associados, como também proteger a plântula contra os microrganismos presentes no solo. Este tipo de tratamento é uma das medidas mais antigas e eficientes de controle de doenças de plantas, sendo normalmente de baixo custo, fácil aplicação e de ação direta na fonte de inóculo do patógeno (Menten, 1995).

Dentre os produtos empregados no tratamento químico de sementes, têm se vários princípios ativos fungicidas recomendados para diversas culturas com objetivo de proteção e manutenção do potencial de produção das plantas (Azevedo, 2001). Para obter-se a máxima eficácia do tratamento químico, deve-se ter a devida cautela na escolha do fungicida ou mistura dos fungicidas a ser aplicada, uma vez que, fatores como modo de ação, eficiência, persistência, aspectos toxicológicos e resistência de microrganismos devem ser considerados (Correa e Marco Júnior, 2013), aspectos que influenciam diretamente no efetivo controle exercido pelo fungicida sobre os patógenos alvos.

Atualmente, existe uma ausência de produtos fitossanitários registrados no Ministério da Agricultura para o tratamento das sementes (AGROFIT, 2019), resultando em uma notória escassez de informações sobre a patologia de sementes de Palma-de-Óleo, existindo a necessidade de analisar o efeito de diferentes tratamentos químicos para o controle de patógenos nas sementes, o qual seja capaz de manejar a micofauna patógena e assim garantir sua qualidade sanitária e fisiológica; da mesma forma, dar suporte ao registro de produtos. Diante do exposto, o objetivo deste trabalho foi avaliar a eficiência de diferentes fungicidas para o controle de fungos em sementes híbridas de Palma-de-Óleo recém beneficiadas e armazenadas.

\section{Material e Métodos}

$\mathrm{Na}$ realização do experimento foram utilizadas sementes híbridas intraespecíficas do tipo Tenera, provenientes do cruzamento de genitores femininos do tipo Dura da origem Deli e masculinos do tipo Pisifera da origem La Mé. As sementes foram produzidas no Campo Experimental do Rio Urubu, município Rio Preto da Eva - AM. Os cachos provenientes da polinização controlada dos genitores foram colhidos no ponto de maturação fisiológica, em torno de 150 dias após a polinização. Após a colheita do cacho as espiguetas foram separadas da ráquis com auxílio de uma machadinha e dispostas em caixas plásticas onde permaneceram por dois dias para a fermentação no intuito de facilitar a despolpa dos frutos, realizada em despolpadora mecânica. Após a despolpa, as sementes foram mantidas em caixas com fundo telado, na sombra, para retirada do excesso de umidade.

O experimento foi realizado no delineamento inteiramente casualizado, em esquema fatorial, consistindo em sete (07) tratamentos com fungicidas e dois (02) tempos de armazenamento, e 10 repetições, sendo cada unidade experimental composta por uma (01) caixa de poliestireno cristal do tipo "gerbox" $(11,0$ x 11,0 x 3,5cm) com 10 sementes. Para aplicação do tratamento fungicida foi composto um lote homogêneo com 1400 sementes, este foi dividido em sete (07) partes 
de 200 sementes, destinadas ao tratamento com seis (06) diferentes fungicidas ou combinação de fungicidas e ao controle, onde foram considerados como tratamento; Testemunha (sem fungicida), Carboxina + Tiram (Vitavax-Thiram ${ }^{\circledR}, 2.0 \mathrm{~mL} \mathrm{~L}^{-1}$ ), Carbendazim (Carbomax $500 \mathrm{sc}^{\circledR}, 20 \mathrm{~mL} \mathrm{~L}^{-1}$ ), Cloridrato de Cartape (Cartap BR 500 $\left.{ }^{\circledR}, 5.0 \mathrm{~g} \mathrm{~L}^{-1}\right)$, Clorotalonil + Tiofanatometílico (Cerconil wp ${ }^{\circledR}, 4.0 \mathrm{~g} \mathrm{~L}^{-1}$ ), Pencicurom (Monceren $250 \mathrm{sc}^{\circledR}, 60 \mathrm{~mL} \mathrm{~L}^{-1}$ ) e Tebuconazol + Trifloxistrobina (Nativo ${ }^{\circledR}, 150 \mathrm{~mL} \mathrm{~L}^{-1}$ ).

As dosagens de cada produto comercial seguiram as orientações técnicas prescritas pelos fabricantes, indicadas em cada produto. Em todos os tratamentos, as sementes permaneceram por três minutos submersas na calda preparada com os fungicidas, e, no caso do controle, em água. Após o período de imersão as sementes foram postas para secar em câmara de exaustão durante 24 horas sobre papel toalha à temperatura ambiente. Ao finalizar a secagem, as sementes foram divididas em duas partes, uma para análise imediata e outra para análise após seis meses de armazenamento. No armazenamento as sementes foram acondicionadas em embalagem plástica, hermeticamente fechada e mantida em sala a $21^{\circ} \mathrm{C}$.

Para detecção dos fungos nas sementes foi empregado o teste de incubação em papel filtro (Blotter test), que consistiu em dispor as sementes em caixas do tipo gerbox, sobre duas folhas de papel filtro, previamente esterilizadas e umedecidas com água destilada até saturação. Em seguida, as caixas foram acondicionadas em sala climatizada, com temperatura de $25^{\circ} \mathrm{C}$, por sete dias, quando então, efetuou-se a observação das estruturas fúngicas com auxílio de microscópio estereoscópico e óptico, para identificar a população fúngica por meio da comparação com as características descritas em literatura (Barnett e Hunter, 1998), identificando os fungos ao nível de gênero. Os resultados foram expressos em incidência média de fungos.

Os dados de incidência fúngica foram submetidos à análise de variância após transformação em $\sqrt{x+0.5}$, uma vez que, a pressuposição de normalidade do desvio $\left(\varepsilon_{i j z}\right)$ não foi satisfeita pelo teste de Shapiro-Wilk. A análise de variância obedeceu ao modelo estatístico:

$$
\mathrm{Y}_{\mathrm{ij}}=\mu+\mathrm{F}_{\mathrm{i}}+\mathrm{T}_{\mathrm{j}}+\mathrm{FT}_{\mathrm{ij}}+\varepsilon_{\mathrm{ij}} \text {, }
$$

em que $Y_{i j}$ é o valor observado nas ordens $i$ (fungicidas) e $\mathrm{j}$ (tempo); $\mu$ é a média da população e
$\mathrm{F}_{\mathrm{i}}, \mathrm{T}_{\mathrm{j}}, \mathrm{FT}_{\mathrm{ij}}$ e $\varepsilon_{\mathrm{ij}}$ são os efeitos de tratamento fungicidas nas sementes, tempo, interação tratamento fungicida/ tempo e erro, respectivamente. As médias foram comparadas pelo teste de Tukey $(\mathrm{p}<0.05)$.

Para a comparação de cada gênero específico nos períodos de tempo analisados foi realizada análise de variância após transformação dos dados em, seguindo o modelo:

$\mathrm{Y}_{\mathrm{ij}}=\mu+\mathrm{T}_{\mathrm{i}}+\varepsilon_{\mathrm{ij}}$

onde, $\mathrm{Y}_{\mathrm{ij}}$ é a incidência do fungo observada na análise i (tempo) e j (repetição); $\mu$ é a média da população, $T_{i}$ é o efeito do tempo no tratamento $i$, e $\varepsilon_{i j}$ representa o efeito do resíduo. Para a comparação do tempo de análise em cada fungo foi utilizado o Teste $\mathrm{T}$ $(\mathrm{p}<0.05)$. Foi utilizada a incidência média e desvio padrão $(\alpha=0.05)$ para comparação dos fungos nos diferentes fungicidas. As análises estatísticas foram realizadas pelo programa SISVAR (Ferreira, 2014).

\section{Resultados e Discussão}

Para a variável incidência de fungos, a análise de variância demonstrou que foram significativos os efeitos de armazenamento, tratamento fitossanitário e da interação entre esses (Tabela 1).

Nas sementes que não passaram por armazenamento, a maior incidência de fungos foi verificada no tratamento controle e com o uso do fungicida Cloridato de Cartape (Figura 1), indicando, portanto, que este produto não teve eficácia no controle dos fungos. Os fungicidas mais eficazes foram Tebuconazol + Trifloxistrobina, Clorotalonil + Tiofanato-metílico e Carbendazim. Já nas sementes que foram armazenadas por seis meses após o

Tabela 1. Resumo da análise de variância para incidência de fungos observada nos diferentes tratamentos fungicidas aplicados em sementes de Palma-de-Óleo analisadas imediatamente após beneficiamento e seis meses após armazenamento

\begin{tabular}{lrrr}
\hline \multicolumn{1}{c}{ FV } & GL & QM & \multicolumn{1}{c}{ F } \\
\hline Tempo de Armazenamento (TA) & 1 & 11.44 & $79.62^{* *}$ \\
Tratamento fungicida (TF) & 6 & 21.13 & $147.02^{* *}$ \\
TA x TF & 6 & 1.17 & $8.18^{* *}$ \\
Resíduo & 126 & 0.14 & \\
\hline CV (\%) & 10.70 \\
\hline \multicolumn{4}{c}{ **Significante a 1\% de probabilidade pelo teste F; FV - Fonte } \\
de variação; GL - Graus de liberdade; QM - Quadrado médio; CV- \\
Coeficiente de variação.
\end{tabular}

Agrotrópica 32(2) 2020 

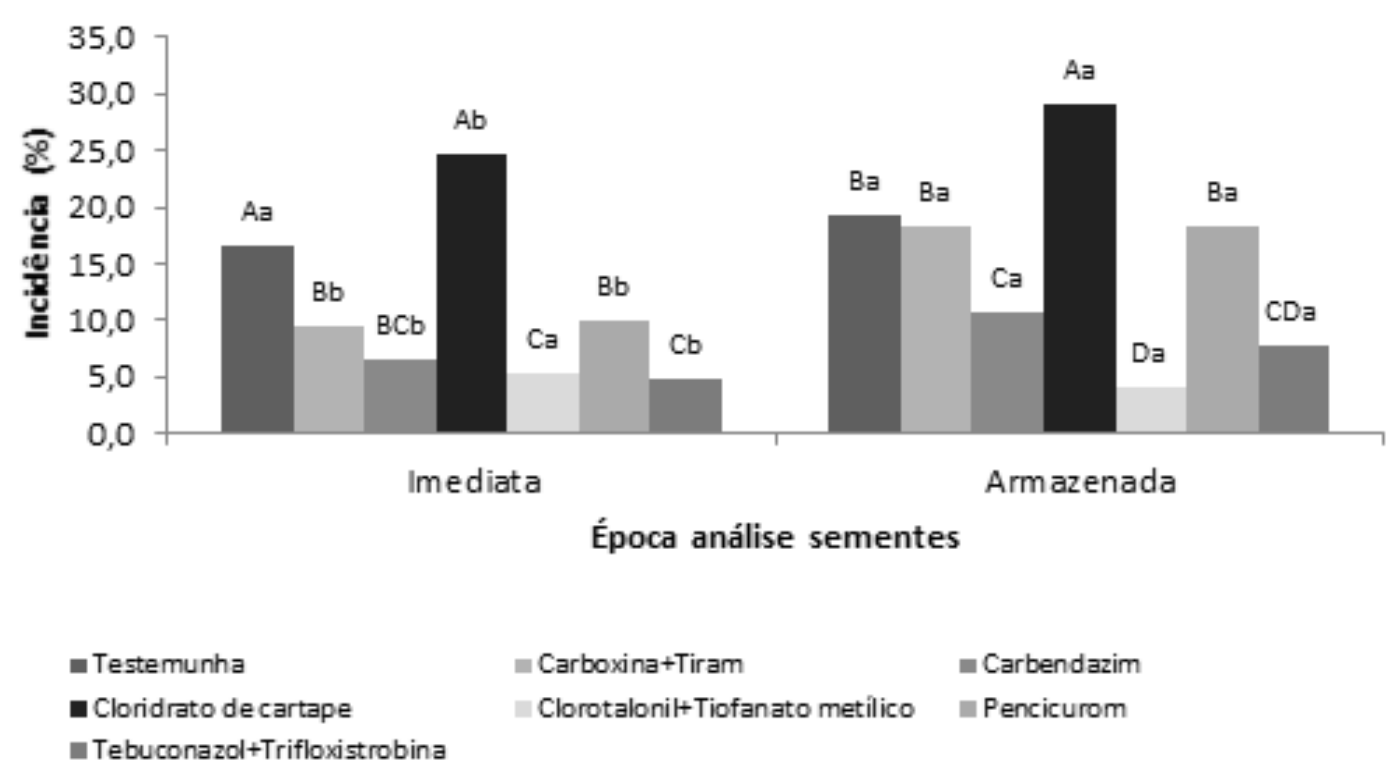

Figura 1. Incidência média (\%) de fungos encontrados nos diferentes princípios ativos fungicidas aplicados em sementes de Palma-de-Óleo analisadas imediatamente após beneficiamento e seis meses após armazenamento. Letras minúsculas iguais não diferem entre as épocas e letras maiúsculas iguais não diferem dentro da época pelo teste de Tukey $(\mathrm{p}<0.05)$.

tratamento fitossanitário, o tratamento com o fungicida Cloridato de Cartape, não foi apenas ineficaz no controle dos fungos como também teve média de incidência superior à verificada em sementes não tratadas. Considerando a média de incidência das sementes não tratadas, além do Cloridato de Cartape, não tiveram eficácia no controle de fungos nas sementes armazenadas os fungicidas Carboxina + Tiram e Pencicurom. Os fungicidas mais eficazes na redução da incidência de fungos nas sementes armazenadas foram Clorotalonil + Tiofanato-metílico e Tebuconazol + Trifloxistrobina, os quais também se destacaram como mais eficazes na redução da incidência de fungos nas sementes não armazenadas, juntamente com o Carbendazim.

Ao comparar a eficiência dos fungicidas na redução da incidência de fungos nas sementes não armazenadas e armazenadas por seis meses, verificou-se aumento da incidência nos tratamentos com todos os fungicidas, exceto com Clorotalonil+Tiofanato-metílico, indicando que este manteve sua eficácia com efeito residual ao longo do período de armazenamento. Considerando que as sementes de Palma-de-Óleo, além de passarem por tempo variável de armazenamento para composição de estoques, são submetidas a processo de quebra de dormência por tratamento térmico por até 75 dias (Lima et al., 2017), o uso de fungicidas que não tenham efeito residual, pode comprometer a qualidade sanitária das sementes devido a perda da eficácia com o tempo de armazenamento.

A ineficácia de fungicidas também foi observada por Gallo et al. (2013), onde este autor destaca que fungicidas indicados para doenças in vivo, não apresentaram eficácia na redução da incidência de fungos quando usados no tratamento de sementes de Aspidosperma desmanthum.

$\mathrm{Na}$ análise da composição da população de patógenos foram identificados oito (08) gêneros de espécies de fungos: Chalariopsis sp., Fusarium sp., Lasiodiplodia sp., Penicillium sp., Rhizoctonia sp., Thielaviopsis sp., Trichoderma sp. e Verticillium sp. $\mathrm{Na}$ análise das sementes que não passaram por armazenamento, os gêneros Rhizoctonia sp e Chalariopsis sp., com 25.1 e $17.8 \%$, respectivamente, se sobressaem estatisticamente aos demais, sendo os mais frequentemente observados nas sementes (Figura 2). E na análise das sementes armazenadas, Rhizoctonia sp (31\%) e Fusarium sp (34.7\%) foram os mais incidentes nas sementes quando comparado aos demais fungos. $\mathrm{O}$ inóculo inicial destes fungos segundo Dikin et al. (2003), são o solo, restos culturais, plantas infestantes e a matéria orgânica em volta das 


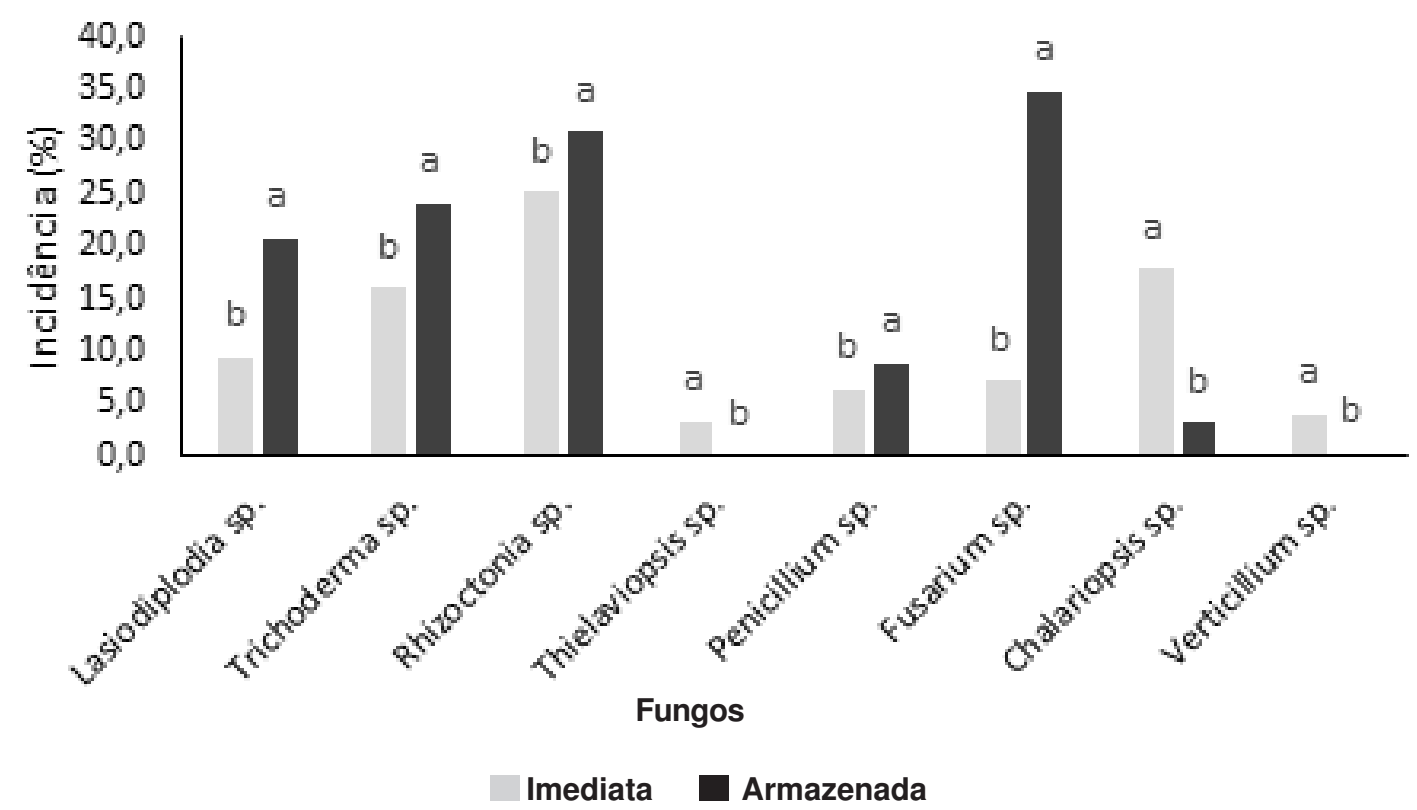

Figura 2. Incidência média (\%) de fungos registrados nos diferentes períodos de tempo avaliados (análise imediata e após seis meses de armazenamento) em sementes de Palma-de-Óleo submetidas a diferentes tratamentos fungicidas. Letras minúsculas iguais não diferem entre as épocas pelo teste $\mathrm{T}(\mathrm{p}<0.05)$.

palmas, que contaminam os frutos machucados durante a prática da colheita. E com o processo de fermentação dos frutos, ocorre o crescimento micelial, penetrando as fibras até atingir as sementes.

$\mathrm{Na}$ comparação entre as duas análises realizadas para cada fungo, observa-se que após armazenamento durante seis (06) meses, mesmo a maior parte das sementes tendo recebido aplicações fungitóxicas, os fungos Lasiodiplodia sp, Trichoderma sp, Rhizoctonia sp, Penicillium sp e Fusarium sp apresentaram um aumento significativo na sua incidência sobre as sementes. Esta observação pode estar relacionada à capacidade de alguns destes organismos desenvolverem seus inóculos em picnídeos (Lasiodiplodia sp.) e escleródios (Rhizoctonia spp.), estruturas capazes de prolongar sua viabilidade mesmo em condições adversas. Fusarium sp. possui esporos pegajosos que facilitam os processos de dispersão e infecção (Carvalho e Nakagawa, 2000), Penicillium $s p$. demanda menor quantidade de água para proliferar em maior intensidade sobre sementes (Barrocas e Machado, 2010) e Trichoderma sp. pode ter sido favorecido pela alta incidência de Rhizoctonia sp e Fusarium sp, uma vez que, nas análises realizadas foi verificada uma frequente associação entre estes fungos. Silva et al. (2007) destaca ainda que Trichoderma sp. é capaz de sintetizar diferentes metabólitos que podem afetar outros organismos no mesmo nicho ecológico, lhe favorecendo em uma possível competição por nutrientes.

Nenhum dos fungicidas testados inibiu completamente o crescimento de todos os fungos envolvidos nos testes (Figura 3). Os agroquímicos utilizados apresentaram os mais diversos efeitos, variando de acordo com o microrganismo alvo. Para Lasiodiplodia sp., ao comparar com a testemunha, somente o Pencicurom não se distinguiu significativamente desta, já para o Penicillium sp., além de Pencicurom, Carboxina+Tiram também não diferiu estatisticamente da incidência observada na testemunha. No entanto, Pencicurom juntamente com Cloridrato de Cartape e Tebuconazol+Trifloxistrobina obtiveram redução significativa em Chalariopsis sp., diferindo dos demais tratamentos.

Para Fusarium sp., os princípios ativos Clorotalonil+Tiofanato-metílico e Tebuconazol + Trifloxistrobina obtiveram a melhor redução significativa, seguido de Carbendazim que apresentou efeito significativamente intermediário na redução deste fungo, e Carboxina+Tiram, Cloridrato de Cartape 


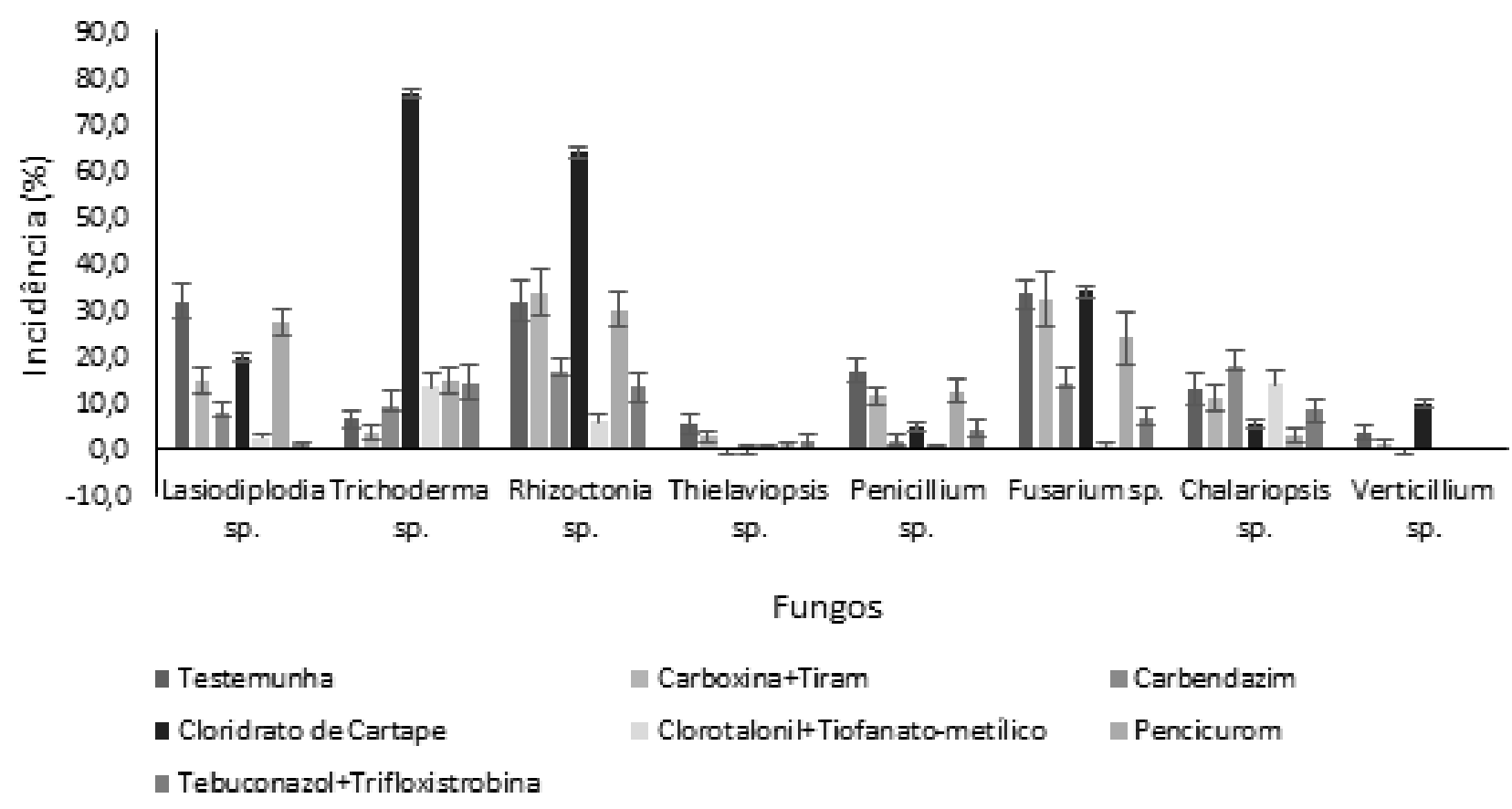

Figura 3. Incidência média (\%) e desvio padrão (á=0.05) da presença de fungos encontrados nos diferentes tratamentos fungicidas em sementes de Palma-de-Óleo recém processadas e armazenadas por seis meses.

e Pencicurom não diferiram estatisticamente da testemunha. Ao considerar Rhizoctonia sp. os produtos Carbendazim, Clorotalonil+Tiofanato-metílico e Tebuconazol + Trifloxistrobina ao comparar a testemunha foi possível observar uma redução na incidência do fungo nas sementes, diferente do Cloridrato de Cartape, que obteve valores médios de incidência superiores até mesmo a testemunha. Já para Trichoderma sp. nenhum tratamento apresentou efeito positivo na inibição deste fungo, sendo que, Cloridrato de Cartape ainda favoreceu significativamente o desenvolvimento deste fungo nas sementes. E, para Thielaviopsis sp. e Verticillium sp. nenhum dos tratamentos diferiu da testemunha, o que pode ter ocorrido pela baixa incidência destes organismos em todos os tratamentos, não sendo possível destacar sensíveis diferenças entre os produtos testados. Muniz, Silva e Blume (2007), relatam condição semelhante, onde, devido à baixa incidência de fungos em sementes florestais não foi possível observar efeito da assepsia na germinação destas sementes.

De maneira geral, Clorotalonil+Tiofanato-metílico, seguido do Tebuconazol+Trifloxistrobina foram os produtos que demonstraram maior eficiência, uma vez que, foi observado uma significativa redução da incidência de fungos como, Lasiodiplodia sp., Rhizoctonia sp., Fusarium sp. e Penicillium sp., os quais possuem algum risco potencial a integridade destas sementes, por serem organismos danosos a cultura da Palma-de-Óleo. Segundo Barcelos et al. (2001), o gênero Lasiodiplodia é responsável por causar manchas foliares em mudas, o que compromete o processo fotossintético destas, e Rhizoctonia sp. causa lesões em folhas jovens, podendo avançar para uma rápida seca após abertura da folha flecha. Já Flood, Mepsted e Cooper (1990) associam o gênero Fusarium a podridões radiculares de plântulas ou da flecha em viveiro. Mora et al. (2007) destacam a ação de Penicillium sp., que pode reduzir o potencial germinativo causando a morte do embrião de sementes de Palma-de-Óleo ou ainda afetando as plântulas após a emergência em pré-viveiro.

Os efeitos positivos no controle de fungos associados aos princípios ativos Clorotalonil + Tiofanato-metílico e Tebuconazol + Trifloxistrobina também foram observados por Cardon et al. (2016) que demonstram a eficiência da mistura Tiofanatometílico+Clorotalonil no controle de crestamento gomoso em melão (Cucumis melo) e para este mesmo princípio ativo, Costa Júnior et al. (2016) obtiveram 
manejo eficiente de Fusarium spp. em sementes de pupunheira (Bactris gasipaes). Santos et al. (2011) destacam o aumento em produtividade de grãos em trigo após aplicação de Tebuconazol+Trifloxistrobina para o controle de doenças foliares. Em milho, Donato e Bonaldo (2013) reduziram a severidade de Cercospora zea-maydis e de Puccinia polysora com o uso de estrobilurinas (Trifloxistrobina), as quais inibem a respiração mitocondrial dos fungos. Já Garcia et al. (2007) recomendam a pulverização com misturas de princípios ativos, pois além de reduzir a doença, evita o surgimento de resistência a fungicidas, o que segundo este autor, põe em risco o controle fitossanitário, contrapondo o uso contínuo de um mesmo produto que pode promover a seleção de fungos resistentes.

O produto comercial a base de Carboxina+Tiram, quando comparado a testemunha, promoveu redução significativa apenas para Lasiodiplodia sp., para os demais fungos, este fungicida obteve taxas de infecção estatisticamente semelhantes a testemunha, portanto, não sendo eficiente para o manejo da micofauna presente nas sementes de Palma-de-Óleo. Esta observação difere de resultados obtidos com este princípio ativo no tratamento de sementes de Elaeis spp. encontrados na literatura (Muhamad et al., 2014; Maquiné et al., 2014), nos quais não foi observada infestação fúngica após o tratamento. A ausência de controle destacada neste estudo pode estar associada ao tempo de exposição das sementes a este produto, uma vez que o tempo aqui utilizado foi dois minutos, inferior ao utilizado nos estudos citados. Como estas sementes possuem impedimento físico na absorção de umidade (Lima et al., 2017), o tempo de imersão das sementes na solução fungicida pode não ter sido suficiente para absorção do princípio ativo, influenciando assim na efetividade do controle de fungos por Carboxina+Tiram.

Os valores de incidência fúngica registrados neste estudo para Carboxina+Tiram contrapõem os observados por Grisi et al. (2009) que ao utilizar este ingrediente ativo reduziu significativamente a presença de Aspergillus sp., Fusarium sp., Penicillium sp., Rhizopus sp. e Rhizoctonia sp. em sementes de girassol (Helianthus annus). Em amendoim (Arachis hypogea), Bittencourt et al. (2007) relataram eficiente controle sobre os patógenos presentes nas sementes, patógenos de solo e após armazenamento com o uso de produtos comerciais a base de Carboxina+Tiram. Segundo Ainie et al. (2007), o princípio Tiram está entre os fungicidas mais comuns utilizados na cultura do Palma-de-Óleo na Malásia, sendo recomendado no tratamento curativo de doenças causadas por Melanconium sp., Glomerella sp. e Rhizoctonia sp. na fase de viveiro (Zainol, Sahid \& Muhamad, 2012).

A alternância de fungicidas com diferentes modos de ação, ou misturas de dois ingredientes ativos com efeito sinérgico, é uma maneira de gerenciar a resistência potencial de fungos ao tratamento químico (Bedin et al., 2008). Desta forma, a eficiência dos ingredientes ativos Clorotalonil+Tiofanato-metílico e Tebuconazol+Trifloxistrobina indicam a possibilidade de seu uso dentro de um sistema de manejo fitossanitário na produção de sementes de Palma-de-Óleo, como nova ferramenta por ser de grupo químico diferentes do normalmente utilizado para o controle desses fungos.

\section{Conclusões}

A aplicação de fungicidas interfere positivamente no manejo de pelo menos uma espécie fúngica associada a sementes de Palma-de-Óleo.

$\mathrm{O}$ agroquímico Clorotalonil+Tiofanato-metílico reduz significativamente a incidência de fungos em sementes de Palma-de-Óleo recém-colhidas e após o armazenamento. Já o princípio Tebuconazol +Trifloxistrobina reduz a população de fungos em sementes recém-colhidas.

$\mathrm{O}$ uso alternado ou combinado de produtos comerciais à base de Clorotalonil+Tiofanato-metílico e Tebuconazol+Trifloxistrobina, ambos eficazes no manejo fitossanitário de sementes de Palma-de-Óleo, pode contribuir para reduzir a pressão de seleção exercida na população de fungos evitando o aparecimento de raças resistentes aos fungicidas.

A escolha do princípio ativo a ser utilizado nas sementes de Palma-de-Óleo deve ser realizada a partir da análise sanitária, de maneira a conhecer os microrganismos específicos presente em cada lote e obter maior eficiência no manejo fitossanitário aplicado.

\section{Agradecimentos}

À Fundação de Amparo à Pesquisa do Estado do Amazonas (FAPEAM) pelo apoio financeiro. 


\section{Literatura Citada}

AGROFIT. AGROTÓXICOS FITOSSANITÁRIOS. Ministério da Agricultura, Pecuária e Abastecimento. 2019. Disponível em: <http://agrofit.agricultura.gov.br/agrofit_cons/ principal_agrofit_cons>. Acesso em: 25 abr 2019.

AINIE, K.; AI, T. Y.; KAMARUDDIN, N.; BENG, Y. C. 2007. Pesticide application in the oil palm plantation. Oil Palm Bulletin, 54:52-67.

AZEVEDO, L. A. S. 2001. Paradigmas da proteção de plantas com fungicidas. In: Azevedo, L.A.S. (ed.). Proteção integrada de plantas com fungicidas. São Paulo, SP. pp.151-160.

BARCELOS, E. et al. 2001. Produção de mudas de dendezeiro na Amazônia. Manaus: Embrapa Amazônia Ocidental. Circular Técnica N. 8. 12p.

BARNETT, H. L.; HUNTER, B. B. 1998. Illustrated genera of imperfect fungi. Ed. 4. Minnesota. The American Phytopathological Society. 218p.

BARROCAS, E. N.; MACHADO, J. C. 2010. Introdução a patologia de sementes e testes convencionais de sanidade de sementes para a detecção de fungos fitopatogênicos. Informativo Abrates 20(3):10-13.

BEDIN, C. et al. 2008. Controle da ferrugem asiática na cultura da soja. Revista Científica Eletrônica de Agronomia 7(13):1-6.

BITTENCOURT, S. R. M. et al. 2007. Eficiência do fungicida carboxin + thiram no tratamento de sementes de amendoim. Revista Brasileira de Sementes 29(2):214-222.

CARDON, C. H. et al. 2016. Eficácia de fungicidas associados a inseticidas sobre o crestamento gomoso do caule e produtividade do meloeiro. Summa Phytopathologica 42(1):79-84.

CARVALHO, N. M.; NAKAGAWA, J. 2000. Sementes: ciência, tecnologia e produção. FUNEP, Jaboticabal, SP. 588p.

CORREA, D.; MARCO JÚNIOR, J. 2013. Efeito do tratamento de sementes com diferentes fungicidas na produção de trigo no Oeste do Paraná. Acta Iguazu 2(2):83-88.

COSTA JUNIOR, J. C. et al. 2016. Qualidade sanitária e fisiológica, métodos de detecção de Fusarium spp. e tratamento de sementes de pupunheira. Ciência Florestal 26(4):1119-1131.

DIKIN, A. et al. 2003. Biological Control of seedborne pathogen of oil palm, Schizopyllum commune Fr. with antagonistic bacteria. International Journal of Agriculture and Biology 5(4):507-512.

DONATO, F. V.; BONALDO, S. M. 2013. Avaliação de diferentes fungicidas no controle de doenças foliares no milho na região norte de Mato Grosso. Enciclopédia Biosfera (Goiânia) 9 (17):375-384.

FERREIRA, D. F. 2014. Sisvar: A Guide for its Bootstrap procedures in multiple comparisons. Ciência e agrotecnologia 38(2):109-112.

FLOOD, J.; MEPSTED, R.; COOPER, R. M. 1990. Contamination of oil palm pollen and seeds by Fusarium spp. Mycological Research 94(5):708-709.
GALLI, J. A.; PANIZI, R. C.; VIEIRA, R. D. 2007. Sobrevivência de patógenos associados a sementes de soja armazenadas durante seis meses. Revista Brasileira de Sementes 29 (2):205-213.

GALLO, R. et al. 2013. Eficiências de Fungicidas em Sementes de Peroba-MICA (Aspidosperma Desmanthum) e seus Efeitos na Germinação. Revista Trópica: Ciências Agrárias e Biológicas 7(2):111-121.

GARCIA, A. et al. 2007. Influência das variáveis ambientais no progresso da antracnose do feijoeiro e eficiência de tiofanato metílico + clorotalonil no controle da doença. Ciência e Agrotecnologia 31(6):1709-1715.

GRISI, P. U. et al. 2009. Qualidade das sementes de girassol tratadas com inseticidas e fungicidas. Bioscience Journal (Uberlândia) 25(4):28-36.

LIMA, W. A. A. et al. 2017. Germinação de Sementes de Elaeis spp. Ed. Embrapa Amazônia Ocidental, Manaus, AM. Circular técnica n. $62.8 \mathrm{p}$.

MAQUINÉ, T. M. et al. 2014. Germination of Seeds of Interspecific Hybrid Caiaué $\times$ Oil Palm Submitted to the Mechanical Depulping. American Journal of Plant Sciences 5:2965-2972.

MENTEN, J. O. M. 1995. Patógenos em sementes: detecção, danos e controle químico. Piracicaba, SP, ESALQ/FEALQ. 312p.

MORA, S. et al. 2007. Innovación en los procesos para mejorar la calidad de las semillas germinadas y de lãs plántulas de palma aceitera. Palmas 28:265-272.

MUHAMAD, H. et al. 2014. Life Cycle Assessment for the Production of Oil Palm Seeds. Tropical Life Sciences Research 2(2):41-51.

MUNIZ, M. F. B.; SILVA, L. M.; BLUME, E. 2007. Influência da assepsia e do substrato na qualidade de sementes e mudas de espécies florestais. Revista Brasileira de Sementes 29(1):140-146.

RIOS, S. A.; CUNHA, R. N. V.; LOPES, R.; BARCELOS, E. 2012. Recursos genéticos da palma de óleo (Elaeis guineensis Jacq.) e caiaué (Elaeis oleifera (H.B.K) Cortés). Manaus, AM, Embrapa Amazônia Ocidental. 39p.

SANTOS, R. et al. 2011. Controle de doenças com fungicidas em trigo. Cascavel 4(2):126-132.

SILVA, G. M. et al. 2007. Fungos associados a sementes de cevadilha vacariana (Bromus auleticus) coletadas nas plantas e no solo. Fitopatologia Brasileira 32(4):353-357.

UNITED STATES DEPARTAMENT OF AGRICULTURE USDA. 2019. Oil Seeds: World Markets and Trade. Circular Series, March 2019. Available: http://www.fas.usda.gov/ psdonline/circulars/oilseeds.pdf. Access: 8 apr 2019.

ZAINOL, M.; SAHID, I.; MUHAMAD, H. 2012. Fate of Thiram in an oil palm nursery during the wet season. Journal of Oil Palm Research 24:1397-1403.

ZIMMER, Y. 2009. Cost competitiveness of major oilseeds versus palm oil. 2009. Acesso em: 15 Abr. 2014. Disponível em: <http://www.agribenchmark.org/fileadmin/ freefiles/ ccteampublications/Zimmer_oilseeds_2009.pdf>. 